\title{
Comparison of three different methods of active and inactive recovery and also sport massage on Aspartate Aminotransferase and aldolase enzyme activations and some hematological blood features in female runners
}

\author{
Rahmani Ghobadi M. ${ }^{1 \mathrm{ABCDE}}$, Hoseini S.A. ${ }^{2 \mathrm{ABCDE}}$, Hasanpour G. ${ }^{2 \mathrm{ABCDE}}$ \\ ${ }^{1}$ Department of Physical Education \& Sport Sciences, Damavand Branch, Islamic Azad University, Damavand, Iran \\ ${ }^{2}$ Department of Physical Education \& Sport Sciences, Marvdasht Branch, Islamic Azad University, Marvdasht, Iran
}

Authors' Contribution: A - Study design; B - Data collection; C - Statistical analysis; D - Manuscript Preparation; E - Funds Collection.

\begin{abstract}
Purpose: $\quad$ Recognizing the periods of rapid recovery and quick return of the body to the normal condition is of particular importance and has been of much interest to the instructors and athletes. The aim of this paper was the comparison of three different of active and inactivate recovery and also sport massage on Aspartate Aminotransferase and Aldolase enzyme activations and some hematological blood features in female runners.

Material: $\quad$ The present study was applied research \& carried out in a semi-experimental manner. This paper's Statistical population includes female semi-professional runners in Tehran \& sampling is done randomly. First, they informed people and asked who were interested to participate in this study. The participants past some basic levels and finally 30 participants (age 18-24 years) semi profession female student runner have been chosen as the sample of this study by their consent randomly. The researchers divided them randomly in 3 groups as active recovery runners, inactive sport massage recovery group and inactive seated group that included 10 participants in each. The importance of this study has been tested by one-way analysis.

Results: $\quad$ The results showed that there is not a meaningful relation among 3 recovery methods for changing Aspartate Aminotransferase and Aldolase enzyme, blood Iron and Red blood cell. But there is a meaningful relation among inactive, soft and massage recovery in changing of White blood cell, Hematocrit and Hemoglobin.

Conclusions: The results of this study showed that the recovery of the primary state through activity compared to the passive state of the effects It's better. According to the results of this study, it seems considering the effect of recycling on the recovery process in athletes, all three types of recycling methods can be used after the athletics competition \& it is recommended that coaches and athletes use these methods more quickly for early onset.

Keywords: aspartate aminotransferase, aldolase enzyme, recovery, sport massage.
\end{abstract}

\section{Introduction}

Recent advances in the field of physical education and sports science and its spread among various societies have attracted researchers' attention to the factors influencing physical activity. Researchers have paid so much attentions to the recent progresses in physical education and sport science recovery or returning to the first base is one of the most important features [1]. Review of Researches on sports success shows that many factors play a role in the development of sports athletes [2]. One of the indicators is successful sport performance, which, apart from the special sports exercises in that discipline, is influenced by other variables, and if not taken into account, the effects of exercise can not affect the athlete's success. One of the most significant variables is the type of recovery or return to the initial state of practice. Meanwhile, using different kinds of recoveries like active recovery, inactive recovery, massage, electric stimulation, using cold water bag, stretching exercise or a combination of all are so important [3, 4].

During complicated hard exercises and competitions, athletes are in exposed of increasing levels of metabolic

\footnotetext{
(c) Rahmani Ghobadi M., Hoseini S.A., Hasanpour G., 2019
}

doi:10.15561/20755279.2019.0205 scum and Traumatic cell features [4]. Small mechanical damages may happen because of different body activities and even in such competitions and exercise that include feet kick to the ground is something inevitable; Therefore, knowing about fast body recovery and returning it to the pre-exercise form and doing normal sport activities is so important [5]. Having a productive exercise session or being in routine competition in professional sport is a base that can prevent from pre-exercising or action reduce [6].

A bad recovery after an exercise session may lead to dysfunction in next exercise session and also long bad recoveries will lead to exhaustion that eventually a bad over exercising situation [7, 8]. Meanwhile, using of different kinds of recoveries such as active, inactive and massage has been super important. Active recovery and massage were being more paid attention among instructors and athletes. The active recovery is popular after a light exercise or even after a serious competition. It is believed that this kind of recovery can improve the performance [9]. Active recovery makes high blood flow that leads to a faster returning in normal.

On the other hand, Massage is being used massively as a relaxing and treating way for athletes to pre- sport, 
between and post preparation in competitions and finally returning to the normal form $[1,5]$. The most important sport massage benefits are the positive massage influence on sport performance, decreasing recovery time to the normal form after exercise and muscle damages, Energy reserves recovery through high blood flow that lead to a better performance in future competitions. Many sport instructors are considering massage in and during the competitions [10]. There is a positive influence on athletes' performance with a faster recovery period by using massage in recess time for different activities that is done in routine $[1,5]$. But you should be aware that sport massage cannot improve body situation after an abnormal exercise [11].

Active recovery means the body returns to its basic level by doing active performance (stretching and fast running for 35 to 40 minutes) after a session of hard exercise. Inactive recovery means the body returns to its basic level by exercise or competition (slow walking, sitting) after a session of exercise. These kinds of recoveries may effect on different metabolic body parts that will change the body situation to continue the exercises or competitions for future sessions that lead to positive or negative effects in further exercising sessions or competitions [4]. These days, most of the athletes use Sport massage as a kinds of recovery to return to the basic form. In this way, by using the sport massage technics after the exercise or a competition, sport massage will start and continue as necessary [1].

Hemoglobin is a protein in red blood cells that transports oxygen from the lungs to the body tissues and carbon dioxide from tissues to the lungs; an ironcontaining respiratory pigment of vertebrate red blood cells that consists of a globin composed of four subunits each of which is linked to a heme molecule, that functions in oxygen transport to the tissues after conversion to oxygenated form in the gills or lungs, and that assists in carbon dioxide transport back to the gills or lungs after surrender of its oxygen [12]. Basically, iron is one the most important component in RBC structure. 30 percent of the iron known as ferritin and stores in the liver, bone marrow and spinal cord. Small percent of body iron is known as transferrin that is responsible to transport iron in enzyme structure and blood cell; Hematocrit is responsible to measure the number of all red cells in blood. In fact, hematocrit is made up of red cells in percent. White cell is produced in lymph nodes, thymus and bone [13]. The white cell numbers in each $\mathrm{m} 2$ is been estimated around 7000 that is so small in comparison of red cells. White cells are responsible to defend the body, they recognize the external pathogen factors and destroy them in different possible way and also there are many kinds of white cells such as neutrophils, lymphocytes, monocytes, Eosinophils and basophils [13]

Red cells are produced in liver, spleen and lymph nodes during the Embryonic and will be made in bone marrow at the final Embryonic months and post birth. Red cells are responsible to transport the oxygen and carbon dioxide. There are more than 5 million of them in one in m3 [9]. AST is being secreted from liver hepatocytes and naturally there is been secreted in different body parts such as liver, heart, muscles, kidney and brain. This enzyme penetrates to blood in case of liver and muscle damage and it's level will increase in blood [14]. The normal level of AST is about 5-40 liter in a unit of serum. When body has a hard exercise, it leads to external muscle damages in skeleton muscle that after 12 hours will increase the AST and remain in our body for 5 days [15].

In this way, the kind of recovery can be related on muscle or cell damage decreasing that can effect on athlete's success. In any sport activity, cell damage starts to secret more than normal in body and if after the competition or exercise it remain in high normal, it can overshadow the athlete's success and performance. ALD is known as an enzyme that is in the heart and Skelton muscles. This enzyme has an important role in changing glucose to lactate and also the level of cell damage and liver issues will increase by this enzyme, too [16]. Athlete's power for doing daily exercises depends on how fast his physiology muscle situation will return to normal [17]. Body will return to the normal form through body liquid replacement, energy storage, damaged body tissue recovery and Metabolic waste disposal [9]. Being aware that sometimes athletes have to participate in more than one competition have many practice sessions to being prepared in just one day in a very short interval, it is very important to know the best recovery way that leads to less sport damages [18].

The levels of athletes' performance during exercising sessions and even in competitions will increase with a good procedure to return to body normal after the exercise; One the necessary practice factor is recovery [19]. When an athlete reaches to the base performance, athlete starts to practice or compete and this is very important due to metabolic and physiologic situation from practice from the base level, the performance will be decreased and when the body form returns to normal (recovery), body system try to back everything to normal and even more than normal (adjusting) and that is what every athlete needs after training sessions. These situations only happen in recovery phase and it is necessary to use the right kind of full detailed recovery [20]. If any athlete cannot use the right recovery after training or competition, definitely will not reach to adjusting level or even maybe will not reach to the base level, either and that means bad performance and cell, muscle damages [17]. Small mechanical damages from different body activities and even in competitions that involve kicking a lot to the ground is inevitable. By using suitable technics, the effects of damages and also Traumatic cell features and metabolic waste from body activities will go through disposal and removal ways that is the most fundamental recovery technics [21]. After the competition or exercise, these features may reach to a higher normal level and it may put the athlete's health and performances in future years if it continues during the exercise or competition. Previous studies mostly have been done on genius athletes to review the active and inactive recovery, but there is been less attention about 
sport massage. So, this is important to be concerned about this matter. By using these recovery post practice or competition technics, we can stop the long term damages in higher levels in the body. Paying attention about this is so important for athlete's health and performance. Therefore, by choosing the right recovery will probably have a positive effect on results. We are aware that there is a proven effect about active recovery against inactive one. there should be much more studies about how to do active and inactive recovery or how should evaluate the results and also what kinds of athletes should be study on.

Hence, we should study more about Traumatic texture and cell so, we should pay more attention about some hematological factors like hemoglobin, hematocrit, iron, red and white cells, AST and ALD. The researcher is going to study 3 methods of active, inactive recovery and sport massage on ALD, AST enzyme activity and some other blood homological on female runners.

\section{Materials and Methods}

\section{Participants}

This is a practical study and it has been used the semi experimental method in crossover way. The sample includes 30 (age 18-24 years) semi profession female student runner by their consent randomly. The data has been gathered by using demographical features questionnaire (physical activity, sport background, health evaluation and medical records) and standard valid laboratory equipment for evaluating the biochemical blood factors like refrigerator, centrifuge machine and counting ELISA Reader machine.

\section{Materials}

The method is semi experiment that has been done lab-field way and controlled with pre and posttest with a control group. We registered participants' demographical and body situation by measuring tools. 30 semiprofessional female runners have been chosen by categorizing randomly based on age, diet (not having special diet), health evaluation (not having special diseases) and body activity evaluation (being or not being athlete) in 3 groups that each group involve 10 members as known active runner recovery, sport massage inactive recovery and inactive being sat recovery groups for study sample. They have been asked to have fast for 10 to 12 hours and after that were taken a blood test from them and sent the samples to be evaluated the specific factors in laboratory. On the competition day, three groups have been chosen to compete. At the end of the competition, blood taking have been done immediately and after that the groups have been asked to do the specific recoveries $[1,22]$.

\section{Procedure}

After the recoveries, the third blood test have been taken. For analyzing the data, we used KolmogorovSmirnov Test for checking data normality, One-way analysis of variance test to check the average differences and intergroup changing in positive level $\mathrm{P}<0.05$ by SPSS $_{22}$ software.

\section{Results}

There was a meaningful relation of White blood cell

Table 1. Pre-test, post-test and recovery of specific variables in study groups.

\begin{tabular}{lllll}
\hline Variable & Measuring time & Groups & & Massage group \\
\hline \multirow{3}{*}{ White blood cell } & Rest group & Slow Running Group & $1312 \pm 6890$ \\
& After practice & $1137 \pm 6530$ & $771 \pm 5930$ & $1236 \pm 9490$ \\
& After recovery & $1525 \pm 6190$ & $593 \pm / 6490$ & $1401 \pm 7400$ \\
Red blood cell & Before practice & $0.61 \pm 5.73$ & $0.67 \pm 5.73$ & $0.82 \pm 5.19$ \\
& After practice & $0.75 \pm 6.34$ & $0.69 \pm 5.89$ & $1.05 \pm 5.96$ \\
Hemoglobin & After recovery & $0.63 \pm 6.19$ & $0.63 \pm 5.70$ & $0.90 \pm 5.67$ \\
& Before practice & $2.00 \pm 15.21$ & $2.07 \pm 15.54$ & $2.22 \pm 13.85$ \\
Blood Iron & After practice & $2.46 \pm 17.45$ & $2.18 \pm 18.88$ & $2.95 \pm 16.41$ \\
& After recovery & $2.49 \pm 16.70$ & $2.11 \pm 15.69$ & $2.47 \pm 15.25$ \\
Hematocrit & Before practice & $44.97 \pm 98.70$ & $48.75 \pm 122.30$ & $52.43 \pm 118.90$ \\
& After practice & $31.75 \pm 117430$ & $34.84 \pm 137.60$ & $45.73 \pm 146.20$ \\
& After recovery & $34.50 \pm 115.10$ & $34.62 \pm 124.20$ & $45.67 \pm 142.30$ \\
ALD & Before practice & $5.49 \pm 46.23$ & $5.94 \pm 46.68$ & $6.68 \pm 41.63$ \\
& After practice & $6.25 \pm 53.22$ & $6.10 \pm 47.97$ & $8.86 \pm 49.31$ \\
& After recovery & $6.61 \pm 50.80$ & $5.90 \pm 47.36$ & $7.45 \pm 45.91$ \\
& Before practice & $2.02 \pm 4.08$ & $1.75 \pm 4.88$ & $1.69 \pm 4.21$ \\
& After practice & $1.09 \pm 1.84$ & $0.39 \pm 1.62$ & $0.67 \pm 1.60$ \\
& After recovery & $1.24 \pm 2.87$ & $0.90 \pm 2.63$ & $1.18 \pm 2.41$ \\
& Before practice & $12.25 \pm 26.80$ & $14.03 \pm 29.80$ & $12.22 \pm 28.00$ \\
& After practice & $10.68 \pm 29.30$ & $14.46 \pm 30.20$ & $12.93 \pm 32.90$ \\
& After recovery & $10.89 \pm 31.80$ & $14.02 \pm 32.30$ & $11.29 \pm 33.20$ \\
\hline \multirow{4}{*}{ ASD } & & &
\end{tabular}


Table 2. One-way analysis of variance test results for variables in post- test.

\begin{tabular}{|c|c|c|c|c|c|c|}
\hline Variable & Statistical index & SS & DF & MS & $\mathbf{F}$ & $\mathbf{P}$ \\
\hline & Between groups & 7646000 & 2 & 3673000 & 3.75 & 0.03 \\
\hline \multirow[t]{3}{*}{ White blood cell } & Within groups & 26400000 & 27 & 977851 & & \\
\hline & Total & 33750000 & 29 & & & \\
\hline & Between groups & 1.17 & 2 & 0.58 & 0.92 & 0.41 \\
\hline \multirow[t]{3}{*}{ Red blood cell } & Within groups & 17.22 & 27 & 0.63 & & \\
\hline & Total & 18.39 & 29 & & & \\
\hline & Between groups & 12.75 & 2 & 74.41 & 1.44 & 0.25 \\
\hline \multirow[t]{3}{*}{ Hemoglobin } & Within groups & 176.67 & 27 & 51.66 & & \\
\hline & Total & 189.42 & 29 & & & \\
\hline & Between groups & 148.82 & 2 & 73.47 & 1.41 & 0.27 \\
\hline \multirow[t]{3}{*}{ Hematocrit } & Within groups & 1394.98 & 27 & 52.68 & & \\
\hline & Total & 1543.80 & 29 & & & \\
\hline & Between groups & 4371.46 & 2 & 2185.73 & 1.52 & 0.23 \\
\hline \multirow[t]{3}{*}{ Blood Iron } & Within groups & 38830.40 & 27 & 1438.16 & & \\
\hline & Total & 43201.86 & 29 & & & \\
\hline & Between groups & 70.20 & 2 & 35.10 & 0.21 & 0.80 \\
\hline \multirow[t]{3}{*}{ ASD } & Within groups & 4418.60 & 27 & 163.65 & & \\
\hline & Total & 4488.80 & 29 & & & \\
\hline & Between groups & 0.35 & 2 & 0.17 & 0.29 & 0.74 \\
\hline \multirow[t]{2}{*}{ ALD } & Within groups & 16.38 & 27 & 0.60 & & \\
\hline & Total & 16.73 & 29 & & & \\
\hline
\end{tabular}

Table 3. One-way analysis of variance to check three different recovery results on variables.

\begin{tabular}{|c|c|c|c|c|c|c|}
\hline Variable & Statistical index & SS & DF & MS & $\mathbf{F}$ & $\mathbf{P}$ \\
\hline & Between groups & 7348382 & 2 & 3674191 & 3.75 & 0.04 \\
\hline \multirow[t]{3}{*}{ White blood cell } & Within groups & 26390000 & 27 & 977358 & & \\
\hline & Total & 33740000 & 29 & & & \\
\hline & Between groups & 0.12 & 2 & 0.06 & 0.77 & 0.47 \\
\hline \multirow[t]{3}{*}{ Red blood cell } & Within groups & 2.21 & 27 & 0.08 & & \\
\hline & Total & 2.33 & 29 & & & \\
\hline & Between groups & 4.74 & 2 & 2.37 & 4.52 & 0.02 \\
\hline \multirow[t]{3}{*}{ Hemoglobin } & Within groups & 14.15 & 27 & 0.52 & & \\
\hline & Total & 18.90 & 29 & & & \\
\hline & Between groups & 40.06 & 2 & 20.03 & 4.10 & 0.02 \\
\hline \multirow[t]{3}{*}{ Hematocrit } & Within groups & 131.72 & 27 & 4.87 & & \\
\hline & Total & 171.79 & 29 & & & \\
\hline & Between groups & 720.06 & 2 & 360.03 & 1.54 & 0.23 \\
\hline \multirow[t]{3}{*}{ Blood Iron } & Within groups & 6281.40 & 27 & 232.64 & & \\
\hline & Total & 7001.46 & 29 & & & \\
\hline & Between groups & 27.46 & 2 & 13.73 & 1.24 & 0.30 \\
\hline \multirow[t]{3}{*}{ ASD } & Within groups & 297.50 & 27 & 11.01 & & \\
\hline & Total & 324.96 & 29 & & & \\
\hline & Between groups & 0.29 & 2 & 0.14 & 0.10 & 0.90 \\
\hline \multirow[t]{2}{*}{ ALD } & Within groups & 40.04 & 27 & 1.48 & & \\
\hline & Total & 40.34 & 29 & & & \\
\hline
\end{tabular}


amounts in semiprofessional female runner's blood in all three groups in post-test results. First, the post-test difference has been computed in all three groups $(\mathrm{P}=0.03$, $\mathrm{F}=3.75)$. The Red blood cell, Hemoglobin, Hematocrit \& iron post-test amounts in female semiprofessional runners was checked by ANOVA one way and there was not a meaningful relation on posttest female semiprofessional runners in all three groups $(\mathrm{F}=0.92, \mathrm{P}=0.41),(\mathrm{F}=1.44$, $\mathrm{P}=0.25),(\mathrm{F}=1.41, \mathrm{P}=0.27),(\mathrm{F}=1.52, \mathrm{P}=0.23)$. There is not a meaningful relation of ASD \& ALD in all three groups. $(\mathrm{F}=0.21, \mathrm{P}=0.80),(\mathrm{F}=0.29, \mathrm{P}=0.74)$.

The LSD follow up test results shows that there is a negative relation between recovery and inactive rest recovery group in White blood cell $(\mathrm{P}=0.01)$. As you see in table 3 , there is not a meaningful relation among three recovery groups for Red blood cell \& iron $(\mathrm{F}=0.77$, $\mathrm{P}=0.47),(\mathrm{F}=1.54, \mathrm{P}=0.23)$. The results showed that there was a meaningful relation among three recovery methods in female semiprofessional runners' Hemoglobin \& Hematocrit changing $(\mathrm{F}=4.52, \mathrm{P}=0.02),(\mathrm{F}=4.10, \mathrm{P}=0.02)$. LSD follow up results showed there is a meaningful relation among soft recovery and inactive rest recovery groups $(\mathrm{P}=0.006)$. The results showed that there is not a meaningful relation among three recovery methods on ASD \& ALD female runners' blood changing. ( $\mathrm{F}=1.24$, $\mathrm{P}=0.30),(\mathrm{F}=0.10, \mathrm{P}=0.90)$.

\section{Discussion}

A person's ability to do the daily exercises depends on how fast the muscles will return to normal phase; This will lead the body return to normal phase by replacing body liquids, energy save and muscle damaged Restoration [13]. Furthermore, with more relaxing and a good nutrition, body will be able to recover the endangered Immune system [11]. Following the right recovery procedure to get back to normal phase after the exercise, the levels of sport performance during practice sessions and in competitions will increase and more important thing is that the body strength will improve.

Recovery will be difficult and complicate after a long term activity and we are able to categorize it in three phases. First phase is called fast level and will happen in first 30 minutes after practice. Then, there is a middle phase that will last 2 hours after the practice and the last phase is the longest that will happen during 20 remain hours and before the next practice session [23].

When the athlete has a few recovery time between the 2 competitions, the fast recovery will be s important because the athlete's best performance on next competition will depends on her fast recovery in a short amount of time [24]. This phase starts when the person finishes her practice and will continue for about 30 minutes. During this time, body will have a slow metabolism and starts to before practice normal level. The heartbeat, breath and body temperature will decrease gradually to resting phase. The blood levels of hormones such as cortisol and testosterone that were up during the exercise will decrease. The muscles' activity starts to replacing CPR and ATP that have been used as energy store, simultaneously. body will start to excrete the extra lactic acid that might be aggregated in muscles.

Most of this lactic acid will penetrate to blood that may become to glucose in liver and inactive muscles. The participants can make body cooling down, metabolic and physiologic procedures faster by light exercises. The exercise will use 40 to 60 percent oxygen for 5 to 10 minutes to keep a faster blood circulation. Keeping the blood circulation higher than normal in this phase will help to excrete lactic acid and transport it to the parts to make more energy [25]. Most body parts and organs like liver, muscle system, active muscle, nervous system, hormonal system, glycogen and muscle tri glyceride and energy system will be under pressure during the competition or a practice session. It is obvious that recovery during or after the sport activity will have a great impact on energy lost levels recovery, blood $\mathrm{pH}$, muscle and body temperature and etc.

Athletes believe that different kind of recoveries and sport massage can have a positive influence on their performances and decrease the return time to normal phase and it can improve the next competition results [26]. Reports shows that there is a physiologic, biomechanics, neurologic and psychologic positive massage effects on body. Nonetheless, based on recent studies there has been a few one about recovery and massage effects to improve muscle exhaustion and increasing sport performance among athletes.

A person's ability to do daily exercises depends on how fast her muscles return to the normal. In this way, body can return to normal phase by replacing liquid, energy saving and muscle damaged recovery. Body can improve Its immune system by enough rest and good nutrition. With a right recovery procedure, body will return to the normal phase very quickly after the exercise sessions and competitions and more important than that body's general health and strength will improve [27].

The results showed that there is not a meaningful relation among 3 recovery methods for changing Aspartate Aminotransferase and Aldolase enzyme, blood Iron and Red blood cell. But there is a meaningful relation among inactive, soft and massage recovery in changing of White blood cell, Hematocrit and Hemoglobin. The results are consistent with the findings of researchers such as Nobahar \& Mirdar, Moenedeor et al [28, 29].

Study of Melekzadeh et al said the amount of combined recovery effect in blood lactate purification, combined and inactive recovery to improve the ability, combined recovery in ability average, combined and active recovery in minimum ability, active combined recovery and sport massage in exhaustion factor, combined recovery and sport massage in exhaustion understanding and having more power are some of other kinds of recovery types. They concluded that combined recovery is the most effective one in blood lactate purification and anaerobe performance improvement, exhaustion understanding and powerfulness toward active and inactive recovery and also sport massage [4].

Nobahar \& Mirdar research results showed that AST amount increased after the 1 st, 4 th and 7 th days of practice 
and it was a meaningful relation but it had a meaningful decreasing after 24-hour rest and there was a meaningful relation with control group on practice days. The amount of CPK increased on 4th and 7 th practice days except the first day. The amount of LDH also increased on 7 th day and after 24-hour rest based on basic levels and also in all levels of blood testing after the practice toward control group. The researchers understood that not paying attention to recovery time based on exercise difficulty may lead to muscle damage and slow performance. These results were Non-aligned with other studies and it is because of the other non-relevant factors such as athlete's perorations, recovery time and etc [28]. Moenedeor et al concluded that returning to normal phase will be categorized in four stages like inactive rest situation, active massage combined rest, massage and active rest. They concluded that massage and active recovery combined can meaningfully decrease performance time. And also active recovery and combined recover may cause Venous blood discharge. but none of these four have any effect on a better heartbeat [29].

\section{Conclusion}

Based on the research results that says there is a positive meaning on white blood cell, hematocrit and hemoglobin in massage recovery, inactive rest sand light running after the competition among female semiprofessional runner, suggest that it is better to use active light running recovery after a track and field math. Also based on the results there is not a meaningful relation on red blood cell changing, iron, ASD and ALD changing in three massage recovery, inactive rest and light running after a sport running activity among female semiprofessional runners. It suggested that they can use all three recovery methods after a track and field matches.

\section{Conflict of interest}

The authors declare no conflict of interest.

\section{References}

1. Arazi H, Asghari E, Mohammad SM, Akbar M. Comparison of the effects of three types of recycling (active / inactive and sports athletic gymnastics) on the 800 and 1500-meter record of university semesters runners). Sport Physiology \& Management Investigations, 2013;10: 49-58.

2. Sarabandi M, Rezaei Z. The Study of the Relationship between Sport Perfectionism and Achievement Motivation with Sport Success: A Case Study Kabaddi Athletes. Sport Psychology Studies, 2017;6(19):57-68.

https://doi.org/10.22089/spsyj.2017.3415.1353

3. Benjamin PJ, Lamp SP (ed). Understanding sports massage. Champaign (IL): Human Kinetics; 2005.

4. Malekzadeh S, Kazemi A, Khodai K. Effect of different types of recovery on some physiologic and psychological factors after intensive training in active male students. Journal of Sport in Biomotor Sciences, 2013;7(1): 42-51.

5. Caruso JF, Coday MA. The combined acute effect of massage, rest periods, and body part elevation on resistance exercise performance. J Strength Cond Res, 2008;22(2): 575- 82. https://doi.org/10.1519/JSC.0b013e3181634d71

6. Stein K. Recovery modalities: An update on the science. Professional baseball athletic trainer's society; 2017.

7. Forghani M, Aliabadi SR, Firozmandi A. The effect of contrast temperature water therapy on blood lactic acid clearance of male students of Mazandaran university of science and technology after exhausting activity. International Journal of Applied Exercise Physiology, 2015;4(2): 51-8.

8. Sharma L, Hussain ME, Verma S. Effect of recovery modalities on blood lactate clearance. Saudi Journal of Sports Medicine, 2017;17(2): 65-6. https://doi.org/10.4103/1319-6308.207577

9. Tabrizi A, Ravasi A, Gaeini A, Gholipour M. The Comparison of the Effects of Active and Passive Recovery on Immune System Indexes after a Graded Exhaustive Exercise in College Athletes. Journal of Sport Biosciences, 2010;2(5): 5-17.

10.Arefinia M, Ghasemi B, Arefinia S, Moradi M. The Effect of Three Methods of Aromatherapy, Massage and Aromatherapy-Massage on Muscular Pain Rate of Female Athletes in Isfahan (Iran). Journal of Sport Medicine, 2013;5(1): 55-68.

11.Galaz GA. An Overview on the history of sports nutrition beverages. In: Nutrition and Enhanced Sports Performance. Academic Press. 2019. P. 231-237 https://doi.org/10.1016/B978-0-12-813922-6.00019-9

12.Mohseni Moghadam F, Shidi-Zandi B, khodadadi-Zadeh A, Sharifzadeh Yazdi Z. Comparison of Hemoglobin A1c Levels in Healthy Patients and Non Diabetic Iron Deficiency Anemia(IDA) Patients Before and after Intervention in Rafsanjan. JSSU, 2009;16(4): 33-40.

13.Nazarali P, Sarvari S, Ramezankhani A. The Effect of Maximal Endurance Training on Hemorheological Factors of National Athletes of Triathlon. Journal of Sport Biosciences, 2013;4(15): 63-75.

14.Fojt E, Ekelund LG, Hultman E. Enzyme activities in hepatic venous blood under strenuous physical exercise. Pflügers Archiv, 1976; 361(3): 287- 96. https://doi.org/10.1007/BF00587294

15.Mena P, Maynar M, Campillo JE. Changes in plasma enzyme activities in professional racing cyclists. British journal of sports medicine, 1996;30(2): 122-24. https://doi.org/10.1136/bjsm.30.2.122

16.Lawlor DA, Sattar N, Smith GD, Ebrahim S. The associations of physical activity and adiposity with alanine aminotransferase and gamma-glutamyltransferase. American journal of epidemiology, 2005; 161(11):1081-88. https://doi.org/10.1093/aje/kwi125

17.Best TM, Hunter R, Wilcox A, Haq F. Effectiveness of sports massageforrecoveryofskeletalmusclefromstrenuousexercise. Clinical Journal of Sport Medicine, 2008; 18(5): 446-460. https://doi.org/10.1097/JSM.0b013e31818837a1

18.Debnath M, Chatterjee S, Sarkar S, Dey SK. Effect of training on muscle cell damage indices and cortisol level in female players of different sports discipline. International Journal of Applied Exercise Physiology, 2019; 8(1): 24-34. https://doi. org/10.30472/ijaep.v8i1.340

19.Gupta S, Goswami A, Sadhukhan AK, Mathur DN. Comparative study of lactate removal in short term massage of extremities, active recovery and a passive recovery period after supramaximal exercise sessions. International journal of sports medicine, 1996; 17(2): 106-10. https://doi.org/10.1055/s-2007-972816

20.Crane JD, Ogborn DI, Cupido C, Melov S, Hubbard A, Bourgeois JM, Tarnopolsky MA. Massage therapy attenuates inflammatory signaling after exercise-induced muscle 
damage. Science translational medicine, 2012; 4(119): 13-14. https://doi.org/10.1126/scitranslmed.3002882

21.ChaudryIH,BlandKI.Cellularmechanismsofinjuryaftermajor trauma. British Journal of Surgery: Incorporating European Journal of Surgery and Swiss Surgery, 2009; 96(10): 1097-98. https://doi.org/10.1002/bjs.6697

22.Ramezanpour MR, Rashid Malmir A, Hesari M. Comparison of the effect of three methods of return to the initial state (mild swimming, sitting and massage) on heart rate and blood lactate in adult swimmers. exercise and bioscience. Journal of Sport and Environmental Sciences Motor, 2011; 2(4): 37-46. (In Persian)

23.Kellmann M. Enhancing recovery: Preventing underperformance in athletes. Human Kinetics; 2002.

24.Hemminge B, Smith M, Graydon J, Dyson R. Effects of massage on physiological restoration, perceived recovery, and repeated sports performance. Journal of Sports Medicine, 2000; 34: 109-115. https://doi.org/10.1136/bjsm.34.2.109

25.Kraemer WJ, Looney DP. Underlying mechanisms and physiology of muscular power. Strength
\& Conditioning Journal, 2012; 34(6): 13-9. https://doi.org/10.1519/SSC.0b013e318270616d

26. Mancinelli CA, Davis DS, Aboulhosn L, Brady M, Eisenhofer J, Foutty S. The effects of massage on delayed onset muscle soreness and physical performance in female collegiate athletes. Phys. Ther. Sport, 2006; 7: 5-13. https://doi.org/10.1016/j.ptsp.2005.10.004

27.Khodaei K. The effect of four active, inactive, massage and combination regimens after intensive exercise on anaerobic function, blood lactate levels, fatigue perception, empathy, and perception of work pressure of physical education students. Quarterly Journal of Student Science, Sports, Development, 2015; 1(2): 7-22.

28.Nobahar M, Mirdar S. The effects of progressive exercise training on some of muscle damage enzymes in active girls. Metabolism and Exercise, 2012; 2(1): 1-12.

29.Monedero J, Donne B. Effect of recovery interventions on lactate removal and subsequent performance. International journal of sports medicine, 2000; 21(8): 593-97. https://doi.org/10.1055/s-2000-8488

\section{Information about the authors:}

Rahmani Ghobadi M.; (Corresponding author); Assistant Professor; http://orcid.org/0000-0002-4948-6895; mrahmani.uni@ gmail.com; Department of Physical Education \& Sport Sciences, Damavand Branch, Islamic Azad University; Moalem Square, Islamic Azad University, Damavand, Tehran Province, Iran.

Hoseini S.A.; http://orcid.org/0000-0001-9122-3952; alihoseini_57@miau.ac.ir; Department of Physical Education \& Sport Sciences, Marvdasht Branch, Islamic Azad University; Marvdasht, Iran.

Hasanpour G.; http://orcid.org/0000-0003-2078-1345; ghobadhasanpour@yahoo.com; Department of Physical Education \& Sport Sciences, Marvdasht Branch, Islamic Azad University; Marvdasht, Iran.

\section{Cite this article as:}

Rahmani Ghobadi M, Hoseini SA, Hasanpour G. Comparison of three different methods of active and inactive recovery and also sport massage on Aspartate Aminotransferase and aldolase enzyme activations and some hematological blood features in female runners. Physical education of students, 2019;23(2):82-88.

https://doi.org/10.15561/20755279.2019.0205

The electronic version of this article is the complete one and can be found online at: https://sportedu.org.ua/index.php/PES/issue/archive

This is an Open Access article distributed under the terms of the Creative Commons Attribution License, which permits unrestricted use, distribution, and reproduction in any medium, provided the original work is properly cited http://creativecommons.org/licenses/by/4.0/deed.en

Received: 14.03.2019

Accepted: 20.04.2019; Published: 28.04.2019 